\title{
A belief system's organization based on a computational model of the dynamic context: first approximation
}

\author{
María Teresa Signes Pont, Higinio Mora Mora, Jorge Azorín López, David Gil Méndez \\ Computer Technology and Computation Department \\ University of Alicante \\ \{teresa, hmora, jazorin, dgil\}@ dtic.ua.es
}

\begin{abstract}
In this paper we present a model of organization of a belief system based on a set of binary recursive functions that characterize the dynamic context that modifies the beliefs. The initial beliefs are modeled by a set of two bit words that grow, update and generate other beliefs as the different experiences of the dynamic context appear. Reason is presented as an emergent effect of the experience on the beliefs. The system presents a layered structure that allows a functional organization of the belief system. Our approach seems suitable to model different ways of thinking and to apply to different realistic scenarios such as ideologies.
\end{abstract}

Key-words. Recursive functions, behavioral patterns, belief system, ideology

\section{1- Introduction}

It is understood that our behavior is the result of both our beliefs and our capability to implement them by means of actions on the world around us. Belief systems are sets of norms that provide a coherent interpretation of the world and allow a viable interaction between humans and society [1,2]. Everybody may have a belief system which is shared totally, partially or not shared with others [3, 4] but belief systems don't deal only with individuals, they also develop social structured organizations that promote attitudes and values in order to provide stability and transmission [5]. The interaction between individuals and organizations and the changes in the world may trigger belief revision [6-9]. Ideology is our most closely held belief system, made of values, feelings and opinions which act as the filter through which we see everything and everybody. Ideologies have played a key role in history by shaping governments and political movements. Political philosophers expound on a variety of political ideologies, or ways of government in order to improve the organization of the societies [10-16]. The study of ideologies is also of great interest for sociologists [17-21], psychologists [22-24], biologists [25, 26] and even computer scientists [27-30].

A definition of belief system is provided by [31]. The authors claim a belief system is a set of related ideas, learned and shared which has some permanence in time and space. They also affirm any belief system is formed by two essential levels denoted the abstract level and the material level, and operates as a cybernetic feedback process. The abstract level is formed by a set of substantive beliefs that are the axioms of the system and by a set of derived beliefs that constitute their theorems. Our proposed belief system considers that experience coming from the dynamic context applies to a few initial embryonic beliefs (substantive beliefs) that grow and increase in number (derived beliefs). The experience modifies the beliefs and next, the emergence of reason completes the updating. We claim reason needs previous beliefs and incoming experience to arise, but in our model, the relationship between cognition and experience 
is not bi-directional as in [1, 31] so, experience doesn't depend on reason and beliefs have no effect upon experience. The beliefs are modeled by binary sequences (binary numbers) and experiences are modeled by a set of recursive functions that transform the sequences. The dynamic context is always enabled so the experiences (functions) can perpetually apply to the beliefs (binary sequences) and transform them again. As a new experience takes place, it applies to both ancient beliefs that are updated (by reason) and new generated beliefs. Ancient beliefs are the sequences with the lower value and the new beliefs are the sequences of the highest value of the rank. The model presents a layered structure that allows a functional organization of the belief system. The paper is organized as follows: after the introduction, Section 2 develops the computational model based on binary local rules that define logic functions by recursive application. These functions exhibit behavioral patterns that combine and build a layered structure that leads to a functional organization of the belief system. Section 3 discusses the details of the organization of the system. Section 4 explains why the model is suitable to approach realistic scenarios and proposes some applications related to ideologies. Section 5 summarizes and presents some concluding remarks.

\section{2- The computational model}

The computational model proposed is based on our own previous research on applications of recursive logic functions $[32,33]$ and stored logic computation $[34,35]$.

\subsection{Definition of binary local rules}

Equation (1) defines binary local rules $\otimes$ as follows:

$$
\begin{aligned}
& \otimes:(0,1) \rightarrow(0,1) \\
& (a, b) \rightarrow c=\otimes(a, b)=a \otimes b
\end{aligned}
$$

The rule is particularized by a two input table so, $16=2^{4}$ different rules (tables) can be defined, see Fig.1: $m$ stands for the index of the table which represents the four bit value stored in the cells, $m=\mathrm{a}_{3} \mathrm{a}_{2} \mathrm{a}_{1} \mathrm{a}_{0}, \mathrm{i} \in[0,3]$ and $\mathrm{a}_{\mathrm{i}} \in(0,1) ; m \in\left[0,2^{4}-1\right]$,

\begin{tabular}{|l|l|l|}
\hline$\otimes$ & $\mathbf{0}$ & $\mathbf{1}$ \\
\hline $\mathbf{0}$ & $\mathrm{a}_{3}$ & $\mathrm{a}_{1}$ \\
\hline $\mathbf{1}$ & $\mathrm{a}_{2}$ & $\mathrm{a}_{0}$ \\
\hline
\end{tabular}

Fig. 1. Generic local rule represented by a table. 
Without loss of generality we set the row operand as the left one and the column operand is the right one in a one dimensional space. For example: $\otimes(0,1)=0 \otimes 1=\mathrm{a}_{1}$ (0 "acts" on 1).

As an example we can consider the rule for $m=\mathrm{a}_{3} \mathrm{a}_{2} \mathrm{a}_{1} \mathrm{a}_{0}=1010$.

So, $0 \otimes 0=1 ; 0 \otimes 1=1 \otimes 1=0 ; 1 \otimes 0=0$

\subsection{Definition of logic functions}

The recursive application of the local rule $\otimes$ defines the functions $f_{m}$ as shown in Equation (2) where p stands for the sequence length (in bits).

$$
\begin{aligned}
& \otimes(0,1)^{p} \rightarrow(0,1)^{p} \\
& \left(x_{p-1} \ldots \ldots x_{1} x_{0}\right) \rightarrow f_{m}\left(x_{p-1} \ldots \ldots x_{1} x_{0}\right)= \\
& \left.\left[\left(\left(\ldots\left(x_{0} \otimes x_{1}\right) \otimes x_{2}\right) \otimes \ldots\right) \otimes x_{p-1}\right] \ldots .\left[\left(\left(x_{0} \otimes x_{1}\right) \otimes x_{2}\right) x_{3}\right]\left[\left(x_{0} \otimes x_{1}\right) \otimes x_{2}\right]\left(x_{0} \otimes x_{1}\right) x_{0}\right)
\end{aligned}
$$

As an example: $m=7=0111 ; f_{7}$ is defined by a table where: $\mathrm{a}_{3}=0, \mathrm{a}_{2}=1, \mathrm{a}_{1}=1, \mathrm{a}_{0}=1$,

for $\mathrm{p}=3$, if $\left(x_{2} x_{1} x_{0}\right)=(101)$, we have $f_{7}\left(x_{2} x_{1} x_{0}\right)=f_{7}(101)=111$,

for $\mathrm{p}=4$, if $\left(x_{3} x_{2} x_{1} x_{0}\right)=(1101)$, we have $f_{7}\left(x_{3} x_{2} x_{1} x_{0}\right)=f_{7}(1101)=1111$,

etc...

We now analyse the functions $f_{m}$ when $\mathrm{p}$ varies by mapping a set of input sequences with different values of $\mathrm{p}$. The left lattice represents the input sequences (rows). See Fig.2. for $f 0$ and Fig.3. for $f 14$. For $\mathrm{p}=2$, we have four possible input sequences of two elements: 00, 01, 10 and 11 (four initial rows). For $\mathrm{p}=3$, we have eight possible input sequences of three elements: 000, 001, 010, 011, 100, 101, 110 and 111 (eight initial rows) and so on. When $\mathrm{p}$ increases one unit, the new input sequences are the previous ones that have been updated by adding a " 0 " as the most significant bit, and the current sequences that have a " 1 " as the most significant value (named MSB, on the left of the number array). Without loss of generality it becomes quite easier to organize all the possible input sequences as if they were decimal values $0,1,2,3$ etc.... The right lattice represents the output sequences after applying recursively the rule $\otimes$ on the input sequences. The corresponding input/output pair is on the same row. It can be observed that the sequence length is preserved and the less significant bit (named LSB, on the right of the number array) is also always preserved. In the output sequences the cursive characters represent the changes that occur on the updated sequences and the bold underlined characters represent the changes that occur on the current input sequences. 
Input sequence

\begin{tabular}{|c|c|c|c|c|c|}
\hline & & 0 & 0 & 0 & $\mathbf{0}$ \\
\hline & & 0 & 0 & 0 & 1 \\
\hline & & 0 & 0 & 1 & 0 \\
\hline & & 0 & 0 & 1 & 1 \\
\hline & & 0 & 1 & 0 & $\mathbf{0}$ \\
\hline & & 0 & 1 & 0 & 1 \\
\hline & & 0 & 1 & 1 & ( \\
\hline & & 0 & 1 & 1 & 1 \\
\hline & & 1 & 0 & 0 & $\mathbf{0}$ \\
\hline & & 1 & 0 & 0 & 1 \\
\hline & & 1 & 0 & 1 & 0 \\
\hline & & 1 & 0 & 1 & 1 \\
\hline & & 1 & 1 & 0 & $\mathbf{0}$ \\
\hline & & 1 & 1 & 0 & 1 \\
\hline & & 1 & 1 & 1 & $\mathbf{0}$ \\
\hline & & 1 & 1 & 1 & 1 \\
\hline
\end{tabular}

Output sequence

fo

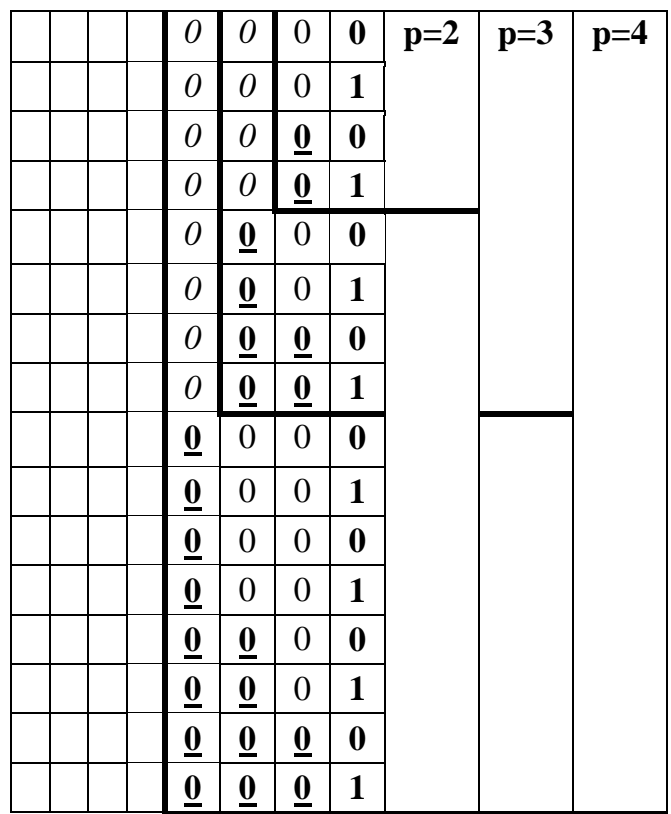

Fig. 2. The function $f 0$ for $\mathrm{p}=2,3$ and 4 .

Input sequence

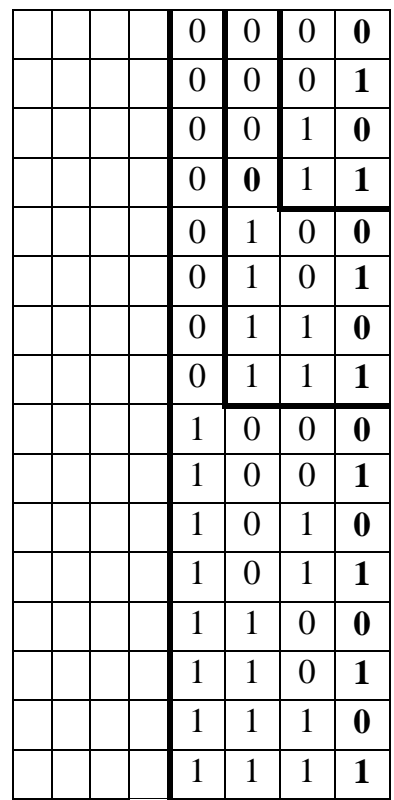

Output sequence

f14

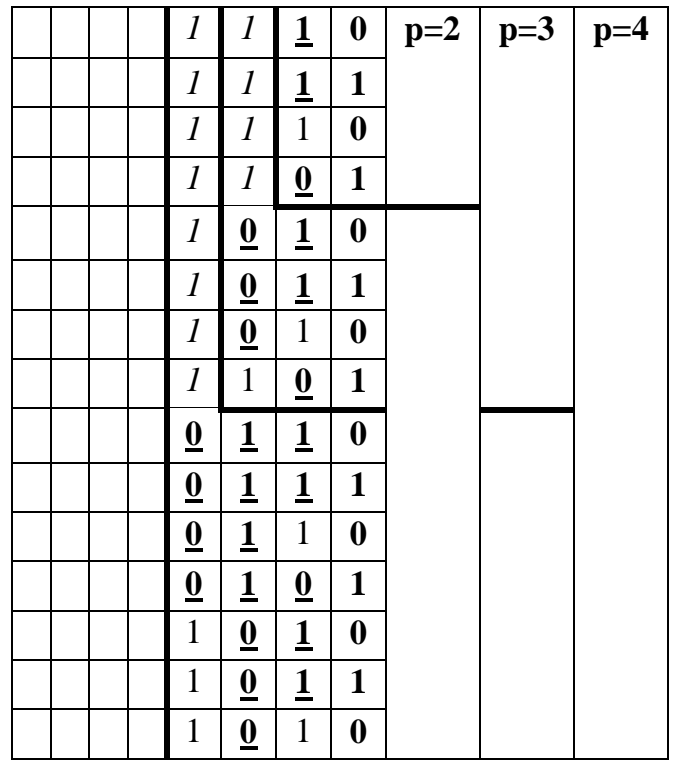




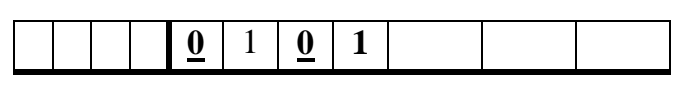

Fig. 3. The function $f 14$ for $\mathrm{p}=2,3$ and 4 .

\subsection{Emergence of behavioral patterns}

The defined functions exhibit behavioral patterns on the output sequences. Two main patterns can be observed:

\section{The updating process: propagation of a value}

The value can be " 1 ", “ 0 ", MSB or MSB' (complement of MSB). The propagation can be

*General: when it is performed on both the current input sequence and the updated sequence irrespective of the input values (no effect on the LSB),

*Forward: when it is only performed on the updated input sequence, irrespective of the input values

*Conditional: when general or forward propagation are performed depending on the input value.

\section{The modification of a value in the sequence}

$$
\begin{aligned}
& \text { "11" changes to " } \mathbf{1 1} " \\
& \text { "01" changes to " } \mathbf{1 1} " \\
& \text { "00" changes to " } \mathbf{1 0 "} \\
& \text { "10" changes to " } 00 "
\end{aligned}
$$

The functions $f_{m}$ are characterized by combinations of these two mains patterns and are structured as follows:

- Layer 0: only propagation

$f 0$ : general propagation of " 0 "

f15: general propagation of " 1 "

f5: general propagation of the LSB.

$f 1$ : if the input sequence is composed of " 1 " then forward propagation of " 0 " (like $f 3$ ) else general propagation of " 0 " (like $f O$ ).

- Layer 1: no change + propagation

f3: forward propagation of " 0 ".

- Layer 2: one change + propagation

$f 2$ : change in the input sequence " 11 " to " 01 "; and then forward propagation of " 0 " 
f7: change in the input sequence " 01 " to " 11 " and then forward propagation of " 1 "

f11: change in the input sequence " 00 " to " 10 " and then forward propagation of the MSB'

- Layer 3: two changes + propagation

f6: changes in the input sequence " 01 " to " 11 " and " 11 " to " 01 " and then forward propagation of the MSB.

f9: changes in the input sequence " 00 " to " 10 " and " 10 " to " 00 " and then forward propagation of the MSB'

f10: changes in the input sequence " 11 " to " 01 " and " 00 " to " 10 " and then forward propagation of the MSB'

- Layer 4: three changes + propagation

f4: changes in the input sequence: " 10 " to " 00 "; " 11 " to " 01 "and " 01 " to " 11 " and then forward propagation of the MSB.

f8: changes in the input sequence " 00 " to " $10 "$ "; " 10 " to " 00 " and " 11 " to " 01 " and then forward propagation of the MSB'

f13: changes in the input sequence " 00 " to " 10 "; " 10 " to " 00 "; " 01 " to " 11 " and then forward propagation of " 1 "

f14: changes in the input sequence " 00 " to " $10 "$ "; " 01 " to " 11 " and " 11 " to " 01 " and then forward propagation of " 1 "

- Layer 5: four changes + propagation

f12: changes in the input sequence " 00 " to " $10 "$ "; 10 " to " 00 "; " 11 " to " 01 " and " 01 " to " 11 " and then forward propagation of " 1 ".

The functions highlight some trends that are divided into two main categories:

1) Hard functions: the output is independent of the input ( $f O$ and $f 15)$ or depends only on the LSB (f5) (Layer 0)

2) Soft functions: the output depends on the input.

* no change is performed on the current input sequence ( $f 3)$, (Layer 1)

* some changes are performed on the current input sequence that are:

** very weak (Layer 2 )

** weak (Layer 3)

** strong (Layer 4)

** very strong (Layer 5)

It must be observed that function $(f 1)$ can be hard (like $f 0$ ) or soft (like $f 3$ ) because its output depends conditionally on the input.

It must be also observed that some soft functions can follow a hard pattern of evolution of the updated sequence because the propagated value is fixed to 0 or 1 and is therefore independent of the current sequence $(f 3, f 2, f 7, f 13, f 14, f 12)$

The following table summarizes the characterization of the functions by their patterns (Fig. 4.) 


\begin{tabular}{|c|c|c|c|c|c|c|c|c|c|c|c|c|c|c|c|}
\hline & \multirow{3}{*}{\multicolumn{4}{|c|}{$\begin{array}{l}\text { Modification of the } \\
\text { current sequence }\end{array}$}} & \multicolumn{11}{|c|}{ Updating process } \\
\hline & & & & & \multirow{2}{*}{\multicolumn{5}{|c|}{ General Propagation }} & \multicolumn{6}{|c|}{ Propagation of the updated sequence } \\
\hline & & & & & & & & & & \multicolumn{5}{|c|}{ Forward } & \multirow[t]{2}{*}{ Conditional } \\
\hline & $\begin{array}{l}\text { "00" } \\
\text { to } \\
\text { "10" }\end{array}$ & $\begin{array}{l}" 10 " \\
\text { to } \\
\text { "00" }\end{array}$ & $\begin{array}{l}\text { "11" } \\
\text { to } \\
\text { " } 01 "\end{array}$ & $\begin{array}{l}\text { "01" } \\
\text { to } \\
\text { "11" }\end{array}$ & "1" & "0" & MSB & $(\mathrm{MSB})^{\prime}$ & LSB & "1" & “0” & MSB & (MSB)' & LSB & \\
\hline \multicolumn{16}{|c|}{$\begin{array}{c}\text { Hard functions } \\
\text { LAYER } 0\end{array}$} \\
\hline fo & & & & & & $\mathrm{X}$ & & & & & & & & & \\
\hline$f 15$ & & & & & $\mathrm{X}$ & & & & & & & & & & \\
\hline$f 5$ & & & & & & & & & $\mathrm{X}$ & & & & & & \\
\hline \multirow[t]{2}{*}{$f 1$} & & & & & & & & & & & $\mathrm{X}$ & & & & $\begin{array}{l}\text { When input } \\
\text { sequence is } \\
\text { "111.....1" }\end{array}$ \\
\hline & & & & & & $\mathrm{X}$ & & & & & & & & & $\begin{array}{l}\text { For any other } \\
\text { input sequence }\end{array}$ \\
\hline \multicolumn{16}{|c|}{ Soft functions } \\
\hline \multicolumn{16}{|c|}{ LAYER 1} \\
\hline$f 3$ & & & & & & & & & & & $\mathrm{X}$ & & & & \\
\hline \multicolumn{16}{|c|}{ LAYER 2} \\
\hline$f 2$ & & & $\mathrm{X}$ & & & & & & & & $\mathrm{X}$ & & & & \\
\hline$f 7$ & & & & $\mathrm{X}$ & & & & & & $\mathrm{X}$ & & & & & \\
\hline$f 11$ & $\mathrm{X}$ & & & & & & & & & & & & $\mathrm{X}$ & & \\
\hline \multicolumn{16}{|c|}{ LAYER 3} \\
\hline f6 & & & $\mathrm{X}$ & $\mathrm{X}$ & & & & & & & & $\mathrm{X}$ & & & \\
\hline fg & $\mathrm{X}$ & $\mathrm{X}$ & & & & & & & & & & & $\mathrm{X}$ & & \\
\hline$f 10$ & $X$ & & $X$ & & & & & & & & & & $X$ & & \\
\hline \multicolumn{16}{|c|}{ LAYER 4} \\
\hline$f 4$ & & $\mathrm{X}$ & $\mathrm{X}$ & $X$ & & & & & & & & $X$ & & & \\
\hline$f 8$ & $\mathrm{X}$ & $\mathrm{X}$ & $\mathrm{X}$ & & & & & & & & & & $\mathrm{X}$ & & \\
\hline$f 13$ & $X$ & $\mathrm{X}$ & & $\mathrm{X}$ & & & & & & $X$ & & & & & \\
\hline$f 14$ & $X$ & & $X$ & $X$ & & & & & & $\mathrm{X}$ & & & & & \\
\hline \multicolumn{16}{|c|}{ LAYER 5} \\
\hline$f 12$ & $\mathrm{X}$ & $X$ & $X$ & $\mathrm{X}$ & & & & & & $X$ & & & & & \\
\hline
\end{tabular}

Fig. 4. Characterization of the functions by their behavioral patterns

\section{3- The belief system model}

Our proposal aims to model the functional organization of a belief system. As claimed by Usó-Nescolarde [1, 31], beliefs, reason and experience are related to each other and the dynamic context provides new experiences that trigger changes in both beliefs and 
ways of reasoning. Our model follows partially this thesis in the sense that the binary growing sequences stand for the beliefs which are transformed by reason and experience. The functions are the powerful tool of the dynamic context which promotes the transformations of the sequences. The modification of the current sequence and the different types of propagation of the updating process shown in Fig.4. represent the transformations of the beliefs triggered by experience and reason respectively. But our approach is more restrictive than [1] because this model doesn't allow for experience to be shaped by beliefs nor reason. We agree with $[1,31]$ in considering that beliefs need experience to be transformed, and reason is the transformation involved in the updating process so, reason is a consequence of the experience which configures a portion of the belief. Reason also needs previous beliefs and incoming experience to arise. The relationships between beliefs, reason and experience are shown in Fig.5.

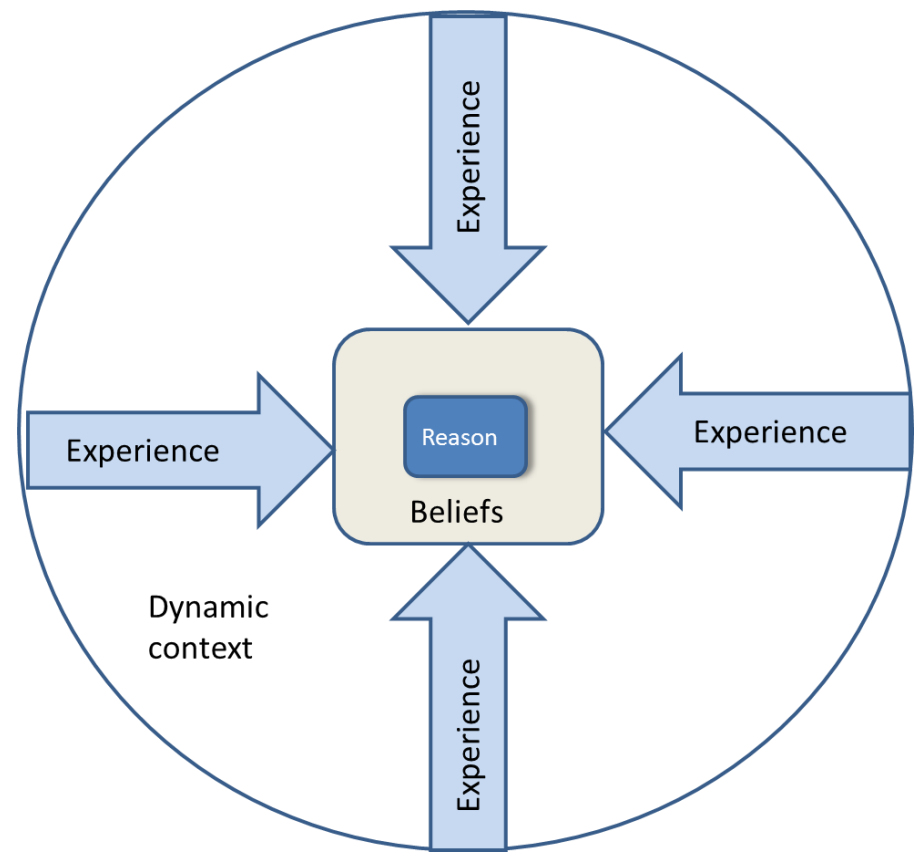

Fig. 5. Relationships between beliefs, reason and experience in our belief system

As defined upper by table Fig.4. our belief system organization is as follows:

- Embryonic beliefs: $\{00,01,10,11\}$

- Experiences $\{f m\}, m \in\left[0,2^{4}-1\right]$,

$\{f m\}$ can apply on the sequences many times. As p increases one unit, a new experience takes place and causes the number of beliefs to double. Generally the previous beliefs are updated (reasoning process) and the new beliefs are modified by experience, but there are exceptions.

The functions belonging to Layer 0 model the rejection or acceptance of a belief without any reasoning process (because they all provide general propagation or forward propagation of a previously fixed value 0 or 1). These are: $f 0$ (full rejection), $f 15$ (full acceptance), $f 5$ (weak rejection/acceptance triggered (only) by the seed value of the previous belief), $f 1$ (conditional full rejection or acceptance of the previous belief "111...1"). 
The function belonging to Layer $1, f 3$, models the acceptance of the previous belief without any reasoning process.

The functions belonging to Layers 2, 3, 4 and 5 model the more or less intense modifications of the previous beliefs and the associated reasoning process $(f 11, f 6, f 9$, $f 10, f 4, f 8)$ or the modifications without any reasoning process $(f 2, f 7, f 13, f 14, f 12)$.

As different experiences always enable, the beliefs are modified many times so, eliminated beliefs can be later reinserted again in the system and accepted beliefs can be later eliminated by means of a new experience. Fig.6. summarizes our belief system's organization.

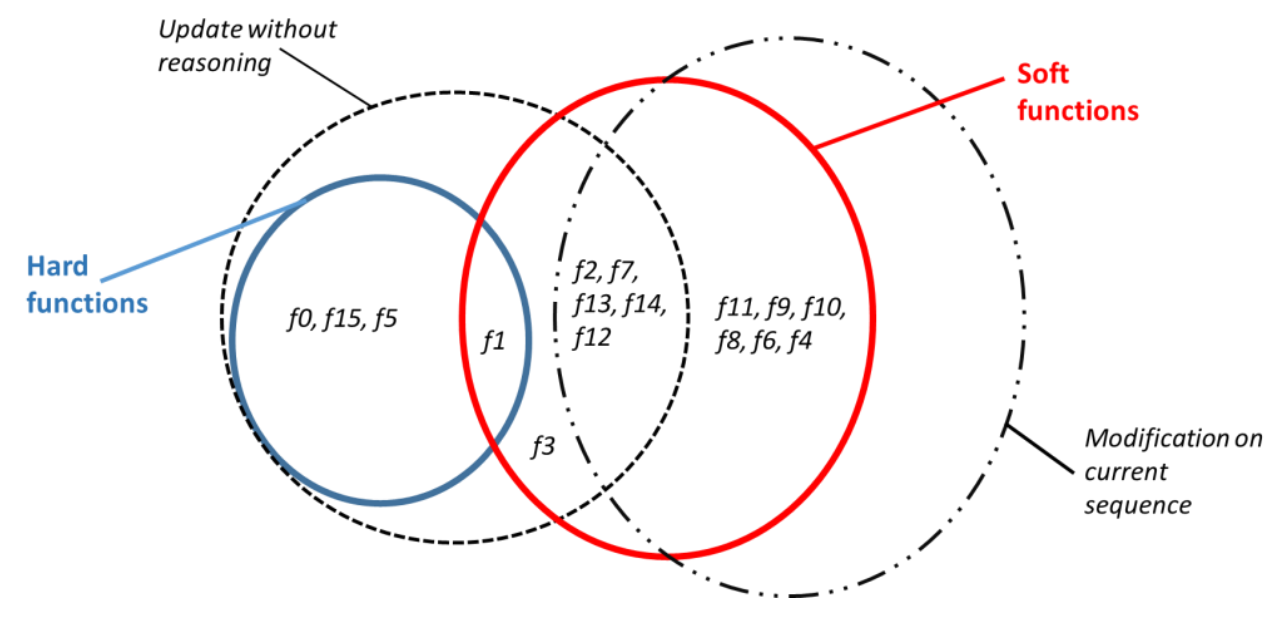

Fig. 6. Model of our belief system's organization

\section{4- Applications}

The applications to realistic scenarios are based on the interpretation we make of the behavioral power of the functions. We first denote as "hard functions" the functions whose input is always mapped into a fixed value with no link with the input (or a very weak link). This mimics the situations that trigger a full drastic rejection or acceptance of a belief, without any reasoning process. "Soft functions" are the functions that consider the previous belief before performing a transformation on it. This represents a larger set of functions that mimics the inheritance of the belief with or without changes. When the inheritance occurs with major or minor changes two different situations appear: the changes can be performed after a reasoning process or without it. The application of the belief system to realistic scenarios is summarized as follows, in Fig.7. Obviously, it is quite premature to claim that this application can exactly mimic the case of ideologies. Ideologies have been extensively studied [36-41] and our approach only aims to connect the functions with different ways of thinking rather than pursuing the study of any ideology. Our proposal analyzes the effects of the characterized functions and places them in a proper ideological context.

It may be interesting to compare our realistic scenarios modeled by functions with the classification presented by Walford [42-44]. This author divides the major ideologies in 
three main groups that are depicted qualitatively (ediostatic centered on concern about the individual, ediodynamic centered on social concern and metadynamic centered on the defeat of ideologies as factors limiting the individual freedom). In the ediostatic group three different ideologies take place, the protostatic ideology, the epistatic ideology and the parastatic ideology. The path between them is obtained by the progressive weakening of the rigid frontier between the individual and his environment. In more concrete terms protostatic ideology may explain fascism or its equivalents. Epistatic ideology can account for conservatism because it allows some changes in order to strengthen the existing situation. In the parastatic ideology the physical sciences have a great influence because they serve in the struggle for survival. The political embodiment of parastatic ideology is liberalism. In the ediodynamic group society is the target against which or within which it is necessary to act in order to improve man's lot. In this group three different ideologies take place, the protodynamic ideology, the epidynamic ideology and the paradynamic ideology. In the protodynamic ideology society is considered as a complex whole that consists of interconnected classes. The improvement comes from structural changes, not from superficial changes. Social democracy is the political manifestation of this ideology. For the epidynamic ideology, antagonism between classes in the society triggers revolution which is an act of liberation. Communism is the associated political manifestation. For the paradynamic ideology the principle of authority that the state uses to control individuals must be removed. This is the ideology of anarchism. With respect to the metadynamic group, ideologies are not a suitable framework to approach problems. This group seeks to defeat ideologies as factors that limit their freedom. In our model, the main consideration is the strength between the output mapping and the input. This strength determines realistic ways of thinking. Soft functions model conservatism, continuity, reformism and revolutionary thinking depending on both the changes between the input and the output and the presence or absence of reasoning process. Hard functions model essentially unsophisticated thinking, such as totalitarianisms and dogmatic thinking or volatile thinking. It can be highlighted that a scenario can be modeled by more than one function. Our approach is more generic in the sense it doesn't not allow modeling concrete ideologies but trends. As an example, rigid thinking could mean communism and/or fascism. More, evolutionary thinking appears as the more complex scenario that can be modeled by six different functions with different degrees of changes and it is the only that includes the reasoning process. This provides flexibility to define several trends in the same way of thinking (reformism, socialism, social democracy, ...). 


\begin{tabular}{|c|c|c|c|c|c|c|}
\hline $\begin{array}{c}\text { Function } \\
\text { type }\end{array}$ & \multicolumn{2}{|c|}{ Characterization } & \multicolumn{2}{|c|}{ Effect } & & $\begin{array}{l}\text { Modeling realistic } \\
\text { scenarios }\end{array}$ \\
\hline \multirow{3}{*}{ Hard } & \multirow{2}{*}{\multicolumn{2}{|c|}{$\begin{array}{l}\text { Maps the input into a fixed } \\
\text { output value with no link } \\
\text { with the input. }\end{array}$}} & \multicolumn{2}{|c|}{$\begin{array}{l}\text { Full drastic rejection of a } \\
\text { belief }\end{array}$} & fo & \multirow{2}{*}{$\begin{array}{l}\text { Dogmatic thinking } \\
\text { (religion...) }\end{array}$} \\
\hline & & & \multicolumn{2}{|c|}{$\begin{array}{l}\text { Full drastic acceptance of a } \\
\text { belief }\end{array}$} & $f 15$ & \\
\hline & \multicolumn{2}{|c|}{$\begin{array}{l}\text { Maps the input into an } \\
\text { output value with a very } \\
\text { weak link with the input. }\end{array}$} & \multicolumn{2}{|c|}{$\begin{array}{l}\text { Weak rejection or acceptance } \\
\text { of a belief }\end{array}$} & $f 5$ & $\begin{array}{l}\text { Volatile thinking } \\
\text { (immature thinking,..) }\end{array}$ \\
\hline Hard/Soft & \multicolumn{2}{|c|}{$\begin{array}{l}\text { Always maps the input } \\
\text { into a fixed output value } \\
\text { with no link with the } \\
\text { input, except when the } \\
\text { input is " } 11 \ldots 1 \text { ". }\end{array}$} & \multicolumn{2}{|c|}{$\begin{array}{l}\text { Conditional rejection of any } \\
\text { belief except belief " } 11 \ldots 1 \text { " } \\
\text { which is accepted without } \\
\text { reasoning process }\end{array}$} & $f 1$ & $\begin{array}{l}\text { Rigid thinking } \\
\text { (totalitarianism,..) }\end{array}$ \\
\hline \multirow{7}{*}{ Soft } & \multirow{7}{*}{$\begin{array}{l}\text { Maps the } \\
\text { input into } \\
\text { an output } \\
\text { value which } \\
\text { depends on } \\
\text { the input }\end{array}$} & No changes & \multirow[t]{2}{*}{$\begin{array}{l}\text { Without } \\
\text { reasoning } \\
\text { process }\end{array}$} & $\begin{array}{l}\text { Inheritance of a } \\
\text { belief without } \\
\text { any } \\
\text { modification }\end{array}$ & $f 3$ & $\begin{array}{l}\text { Traditional thinking } \\
\text { transmission } \\
(\text { conservatism...) }\end{array}$ \\
\hline & & \multirow[t]{2}{*}{1 change } & & $\begin{array}{l}\text { Inheritance of a } \\
\text { belief and weak } \\
\text { modification }\end{array}$ & $\begin{array}{l}f 2 \\
f 7\end{array}$ & $\begin{array}{l}\text { Traditional thinking } \\
\text { transmission with } \\
\text { minor aesthetic } \\
\text { changes (continuity) }\end{array}$ \\
\hline & & & \multirow{3}{*}{$\begin{array}{l}\text { With } \\
\text { reasoning } \\
\text { process }\end{array}$} & \multirow{3}{*}{$\begin{array}{l}\text { Inheritance of a } \\
\text { belief and } \\
\text { progressive } \\
\text { modification }\end{array}$} & $f 11$ & \multirow{3}{*}{$\begin{array}{l}\text { Evolutionary thinking } \\
\text { (reformism, ...) }\end{array}$} \\
\hline & & 2 changes & & & $\begin{array}{l}f 6 \\
f 9 \\
f 10\end{array}$ & \\
\hline & & \multirow[t]{2}{*}{3 changes } & & & $\begin{array}{l}f 4 \\
f 8\end{array}$ & \\
\hline & & & \multirow{2}{*}{$\begin{array}{l}\text { Without } \\
\text { reasoning } \\
\text { process }\end{array}$} & \multirow{2}{*}{$\begin{array}{l}\text { Inheritance of a } \\
\text { belief and full } \\
\text { modification }\end{array}$} & $\begin{array}{l}f 13 \\
f 14\end{array}$ & \multirow{2}{*}{$\begin{array}{l}\text { Remove the inherited } \\
\text { thinking and replace } \\
\text { it with another } \\
\text { (revolutionary } \\
\text { thinking, ...) }\end{array}$} \\
\hline & & 4 changes & & & $f 12$ & \\
\hline
\end{tabular}

Fig. 7. Application of the belief model to realistic scenarios

\section{5- Conclusion}


In this paper we have presented a belief system organization based on a computational model of the dynamic context. The model focuses on a set of functions that apply recursively on beliefs to model the incoming experience coming from the dynamic context. The initial beliefs are modeled by two bit words that grow, update and generate other beliefs as the different experiences of the dynamic context appear. Reason is presented as an emergent effect triggered by experience. This approach provides a layered structure which highlights how the changes are performed on the beliefs, and is suitable to depict realistic scenarios relative to different ways of thinking such as dogmatic thinking, traditional thinking, or evolutionary thinking.

\section{References}

[1] Nescolarde-Selva, J. A systemic vision of belief systems and ideologies. Ph.D. Department of Applied Mathematics. University of Alicante. Alicante. Spain.

[2] Martin, J. L. (2002). Power, authority and the constraint of belief systems. American Journal of Sociology, 107(4), 861-905. Retrieved October 23, 2003 from Ebsco Host database.

[3] Frank, L. (1951). Nature and human nature. Man's new image of himself. New Jersey: Rutgers University Press.

[4] Gitelson, G., Bing, J., and Laroche, L. (2001). Culture shock. CMA Management, 41-44. Henry III, W. A. (1990).

[5] Garzón, A. (2006). Evolución de las Creencias Sociales en España. Boletín de Psicología, 86, 53-84

[6] Dixon, E. (1994). Belief Revision: A Computational Approach

[7] Luam, S. (2005). A computational framework for belief change. Springer-Verlag Berlin

[8] Ingelhart, R. (2005). Modernization, cultural change and democracy. The Human Development Sequence. Cambridge: Cambridge University Press.

[9] Ingelhart, R. (2008). Changing values among Western. Cambridge: Cambridge University Press. Publics from 1970 to 2006. West European Politics, 31(1-2), 130-146

[10] Eagleton, Terry (1991) Ideology. An introduction. Verso.

[11] James, P. and Steger, M. (2010). Globalization and Culture, Vol. 4: Ideologies of Globalism. London: Sage Publications.

[12] Blattberg, Charles, "Political Philosophies and Political Ideologies," in Patriotic Elaborations: Essays in Practical Philosophy, Montreal and Kingston: McGill-Queen's University Press, 2009.

[13] Freeden, Michael. 1996. Ideologies and Political Theory: A Conceptual Approach. Oxford: Oxford University Press.

[14] Haas, Mark L. (2005). The Ideological Origins of Great Power Politics, 1789-1989. Cornell University Press,

[15] Owen, J. (2011). The Clash of Ideas in World Politics: Transnational Networks, States, and Regime Change, 1510-2010", Princeton University Press,

[16] Jost, J. T. et al. (2008). Shared reality, system justification and the relational basis of ideological beliefs. Social and Personality Psychology Compass, 2,171-186

[17] Seoane, J., y Garzón, A. (1996). El marco de investigación del Sistema de Creencias Post modernas. Psicología Política, 13, 81-98. 
[18] Freeden, M. (2010). Social and psychological bases of ideology and system justification - Edited by John T. Jost, Aaron C.

[19] Hagan, J., \& Rymond-Richmond, W. (2008). The collective dynamics of racial dehumanization and genocidal victimization in Darfur. American Sociological Review, 73, 875-902.

[20] Howarth, D., Norval, A., \& Stavrakakis, Y. (2000). Discourse theory and political analysis: Identities, hegemonies and social change. Manchester, United Kingdom: Manchester University Press.

[21] Leader Maynard, J. (2013). A map of the field of ideological analysis. Journal of Political Ideologies, 18, 299-327.

[22] Haidt, J., Graham, J., \& Joseph, C. (2009). Above and below left-right: Ideological narratives and moral foundations. Psychological Inquiry, 20, 110-119.

[23] Jost, J. T., Glaser, J., Kruglanski, A. W., \& Sulloway, F. J. (2003). Political conservatism as motivated social cognition. Psychological Bulletin, 129, 339-375.

[24] Homer-Dixon, T et al. A Complex Systems Approach to the Study of Ideology: Cognitive-Affective Structures and the Dynamics of Belief Systems. Journal of Social and Political Psychology 2013, Vol. 1(1), 337-363.

[25] Alford, J. R., Funk, C. L., \& Hibbing, J. R. (2005). Are political orientations genetically transmitted? American Political Science Review, 99, 153-167

[26] Amodio, D. M., Jost, J., Master, S. L., \& Yee, C. M. (2007). Neurocognitive correlates of liberalism and conservatism. Nature Neuroscience, 10, 1246-1247

[27] Gell-Mann, M. (1997). The simple and the complex. In D. Alberts \& T. Czerwinski (Eds.), Complexity, global politics, and national security (pp. 3-28). Washington, DC: National Defense University.

[28] Lang, J., \& De Sterck, H. (2012). The Arab Spring: A simple compartmental model for the dynamics of a revolution. arXiv: $1210.1841 \mathrm{v} 1$.

[29] Squazzoni, F. (2012). Agent-based computational sociology. Chichester, United Kingdom: Wiley. Journal of Social and Political Psychology 2013, Vol. 1(1), 337-363

[30] Sobkowicz, P. (2009). Modelling opinion formation with physics tools: Call for closer link with reality. Journal of Artificial Societies and Social Simulation, 12(1), Article 11. Retrieved from http://jasss.soc.surrey.ac.uk/12/1/11.html

[31] Nescolarde-Selva, J. and Usó-Doménech, J.L., Topological Structures o Complex Belief Systems. Complexity, Vol 19(1), pp.46-62.

[32] Signes, M.T.; Mora, H.; Mora, J.; García, J.M., (2014), An approach to stigmergy issues based on the recursive applications of binary elementary operations, World Conference on Information Systems and Technologies

[33] Signes, M.T.; Mora, H.; Mora, J.; García, J.M., (2012), An Approach to Computations in Living Tissues Based on Logic Functions, EUROMICRO International Conference on Parallel, Distributed and Network-based Processing.

[34] Mora-Mora, H.; Mora-Pascual, J.; Signes-Pont, M.T.; Sánchez-Romero, J.L., (2010), Mathematical model of stored logic based computation, Mathematical and Computer Modelling 52 (7), pp. 1243-1250.

[35] García Chamizo, J.M.; Mora Pascual, J.; Mora Mora, H.; Signes Pont, M.T., (2003), Calculation Methodology for Flexible Arithmetic Processing, International Conference on Very Large Scale Integration of Systems-on-Chip, pp.350-355. 
[36] Berger, P. and Luckmann, T. The Social Construction of Reality. Garden City, Doubleday. New York. 1966.

[37] Borhek, J.T. and Curtis, R.F. A Sociology of Belief. Robert E. Krieger Publishing Company. Malabar. Florida. 1983.

[38] Crossman. R.H.S. The God That Failed. Harper \& Row. New York. 1949.

[39] Durkheim, E. The Elementary Forms of the Religious Life. The Free Press. New York. 1965.

[40] Fromm, E. The Sane Society. Routledge. London. 2002.

[41] Rokeach, M. Beliefs, Attitudes and Values. Jossey-Bass. San Francisco. 1968.

[42] Walford, G. Ideologies and their Functions; a Study in Systematic Ideology. The Bookshop, 1979.

[43] Walford, G. Systematic Ideology, the Work of Harold Walsby. Science and Public Policy, February, pp. $27-33.1983 a$.

[44] Walford, G. Beyond Ecology. Science and Public Policy. pp. 244 - 50. 1983b. 